\title{
SQUIRRELnovo: de novo design of a PPAR $\alpha$ agonist by bioisosteric
} replacement

\author{
E Proschak*, K Sander, H Zettl, Y Tanrikulu, P Schneider, O Rau, H Stark, \\ M Schubert-Zsilavecz and G Schneider
}

Address: Goethe-University Frankfurt am Main, Siesmayerstr. 70, D-60323 Frankfurt am Main, Germany

* Corresponding author

from 4th German Conference on Chemoinformatics

Goslar, Germany. 9-II November 2008

Published: 5 June 2009

Chemistry Central Journal 2009, 3(Suppl I):O4 doi:I0.II86/I752-I53X-3-SI-O4

This abstract is available from: http://www.journal.chemistrycentral.com/content/3/SI/O4

(C) 2009 Proschak et al; licensee BioMed Central Ltd.

Shape complementarity is a compulsory condition for molecular recognition [1]. In our 3D ligand-based virtual screening approach called SQUIRREL, we combine shapebased rigid body alignment [2] with fuzzy pharmacophore scoring [3]. Retrospective validation studies demonstrate the superiority of methods which combine both shape and pharmacophore information on the family of peroxisome proliferator-activated receptors (PPARs). We demonstrate the real-life applicability of SQUIRREL by a prospective virtual screening study, where a potent PPAR $\alpha$ agonist with an EC50 of $44 \mathrm{nM}$ and 100-fold selectivity against PPAR $\gamma$ has been identified.

SQUIRREL molecular superposition is based on a graphmatching routine [4] and allows partial matching. We used this advantage for searching for bioisosteric replacement suggestions in a database of molecular fragments derived from a collection of drug-like compounds [5]. The bioisosteric groups suggested by our tool SQURRELnovo, can be used for ligand-based de novo design by a human expert. Using the fibrate derivative GW590735 [6] as query, we designed a novel lead structure by substitution of the acidic head group and hydrophobic tail. The synthesis and following testing in a cell-based reporter gene assay $[7,8]$ revealed that the designed structure activates PPAR $\alpha$ with an EC50 of $510 \mathrm{nM}$.

\section{References}

I. Schneider G, Baringhaus K-H: Molecular Design - Concepts and Applications. Wiley-VCH: Weinheim, New York; 2008.

2. Proschak, et al.: J Comput Chem 2008, 29: 108.
Tanrikulu , et al.: Chem Bio Chem 2007, 8:1932.

Bron C, Kerbosch J: Communications of the ACM 1973, 16:575-577.

Schneider P, Schneider G: QSAR Comb Sci 2003, 22:713-7I8.

Sierra, et al.: J Med Chem 2007, 50:685.

Rau, et al.: Planta Med 2006, 72:881.

Derksen, et al:: Chem Med Chem 2006, I:1346. 